\title{
Total glucosides of peony induce fibroblast-like synovial apoptosis, and ameliorate cartilage injury via blocking the NF-кB/ STAT3 pathway
}

\author{
Min Fu, Xiaoxiao Sang, Hongxia Cheng \\ College of Biological and Pharmaceutical Engineering, Wuhan Huaxia University of Technology, Wuhan, China \\ Contributions: (I) Conception and design: M Fu, X Sang; (II) Administrative support: H Cheng; (III) Provision of study materials or patients: M Fu, \\ X Sang; (IV) Collection and assembly of data: X Sang; (V) Data analysis and interpretation: M Fu, H Cheng; (VI) Manuscript writing: All authors; (VII) \\ Final approval of manuscript: All authors. \\ Correspondence to: Hongxia Cheng. Wuhan Huaxia University of Technology, 589 Guanshan Avenue, Wuhan 430223, China. Email: chenghx122@163.com.
}

Background: Rheumatoid arthritis (RA) is one of the most common inflammatory arthritis worldwide. Total glucosides of peony (PG) were isolated from Paeonia lactiflora Pall, which were found to have the capacity to intervene in the progression of arthritis via an anti-inflammatory action. This study aimed to explore the protective effect of PG against RA.

Methods: In this study, we further investigated the molecular mechanisms of PG on RA. We constructed RA models by Bovine type II collagen in vitro or complete Freund's adjuvant (FCA) in vivo. The RA-MH7A cells were cultured and treated with different doses $(10,20,50 \mu \mathrm{g} / \mathrm{mL})$ of PG. Cell proliferation, apoptosis, and release of inflammatory cytokines were determined. Furthermore, the effect of PG was also explored in vivo using the collagen-induced arthritis rat model. After 30 days, the rats were sacrificed; histological changes, cytokine level, and protein expression were measured.

Results: It was revealed that PG dose-dependently inhibited RA-synovial cell growth and induce apoptosis by regulating relative gene level. Besides, PG downregulated the levels of interleukin (IL)-6, tumor necrosis factor- $\alpha(\mathrm{TNF}-\alpha)$ and IL-1 $\beta$, and upregulated IL-10 level in vitro and in vivo. The regulation contributed to the restoration of cartilage injuries. Furthermore, PG also downregulated the expression of nuclear factorkappa B (NF- $\mathrm{B}$ ) and signal transducer and activator of transcription 3 (STAT3) phosphorylation.

Conclusions: All these results showed that PG inhibits the excessive proliferation of synovial cells, and ameliorates cartilage injury via blocking the NF- $\mathrm{B} / \mathrm{STAT} 3$ pathway. Collectively, this study provides novel insights into the mechanism of PG, laying a foundation for the application of PG in RA.

Keywords: Rheumatoid arthritis (RA); total glucosides of peony (PG); cartilage injury; anti-inflammatory; NFผB/STAT3

Submitted Oct 31, 2021. Accepted for publication Jan 05, 2022.

doi: 10.21037/atm-21-6187

View this article at: https://dx.doi.org/10.21037/atm-21-6187

\section{Introduction}

Rheumatoid arthritis (RA) is a chronic systemic disease characterized by synovial hyperplasia and inflammatory cell infiltration (1). The basic pathological features of RA are proliferation and invasion of synovium, formation of invasive pannus, and destruction of bone and cartilage $(2,3)$. Currently, approximately $1.0 \%$ of the global population have RA (4,5). It might cause many other health problems such as cardiopathy, nephropathy, vasculopathy, pulmonary, and cutaneous disorders, eventually leading to death (6). Clinically, therapeutic drugs such as non-steroidal drugs, glucocorticoids, antirheumatic drugs, and biological agents have notable side-effects, which cause many other physical diseases (7-9). 
Traditional Chinese medical herbs have a wide range of sources and many natural substances with little side-effect. The total glucosides of peony (PG) is a bioactive constituent isolated from Paeonia lactiflora Pall. About $90 \%$ of the ingredients in PG are paeoniflorin (10). It has numerous benefits for human health, including anti-inflammatory and anti-analgesic (11), immunoregulatory actions (12), and antioxidant properties (13). Accumulating evidence has indicated that PG dramatically ameliorates various diseases such as Sjögren's syndrome (14), diabetic nephropathy (15), autoimmune uveitis (16), oral lichen planus (17), prostate cancer (18), and RA (19). In China, PG was recognized as a disease-modifying drug for RA by the China Food and Drug Administration in 1998.

Nuclear factor-kappa $B(N F-\kappa B)$ is an important transcriptional protein that regulates multiple inflammatory factors and can be found in almost all animal cells. Both $\mathrm{NF}-\mathrm{\kappa B}$ and nuclear translocation of signal transducer and activator of transcription 3 (STAT3) play important roles in the pathogenesis of RA-associated inflammation (20). Wang et al. reported that PG suppressed the dissociation of I $\mathrm{B} \alpha$ and reduced the levels of interleukin (IL)- 6 and tumor necrosis factor- $\alpha$ (TNF- $\alpha$ ) in oral lichen planus (17). Besides, PG has been reported to promote macrophage proliferation by activating the JAK2/STAT3 pathway in diabetic nephropathy rats (21). Nevertheless, as an important drug of RA, the deeper molecular mechanisms of PG are still unclassified.

In this study, we explored the deep molecular mechanisms of PG in RA. This is the first time that PG can attenuate inflammatory response both in vitro and in vivo. Our findings indicated that PG mitigates RA by suppressing the excessive proliferation of synovial cells, cartilage injury, and inflammation via deactivating the NF- $\mathrm{KB} / \mathrm{STAT} 3$ pathway.

We present the following article in accordance with the ARRIVE reporting checklist (available at https://atm. amegroups.com/article/view/10.21037/atm-21-6187/rc).

\section{Methods}

\section{Cell culture and treatment}

The human RA synovial fibroblasts MH7A was purchased from Riken (Saitama, Japan) and grew in Roswell Park Memorial Institute (RPMI) 1640 (Gibco, Waltham, MA, USA) supplemented with $10 \%$ fetal bovine serum (FBS; Gibco, Waltham, MA, USA), $100 \mu \mathrm{g} / \mathrm{mL}$ streptomycin and $100 \mathrm{U} / \mathrm{mL}$ penicillin (Invitrogen, Carlsbad, CA,
USA). Lyophilized bovine type II collagen (C II) powder was dissolved in acetic acid $(0.05 \mathrm{M})$ at a concentration of $2.0 \mathrm{mg} / \mathrm{mL}$. Then, cells were induced by Collagen II (C II, Sigma-Aldrich Co. St. Louis, MO, USA) for $24 \mathrm{~h}$. PG (purity $>98 \%$ ) were purchased from Nantong Feiyu Biological Technology Co., Ltd. (Nantong, Jiangsu, China), which chemical formula was illustrated in Figure $1 \mathrm{~A}$. The stock solution of PG $(1 \mathrm{mg} / \mathrm{mL})$ was diluted with RPMI 1640 until the final concentrations were 10, 20, and $50 \mu \mathrm{g} / \mathrm{mL}$, respectively (22). The MH7A cells were grouped as follows: the control group: MH7A cells without any treatment; collagen induced RA model group (RA); RA + PG $(10,20,50 \mu \mathrm{g} / \mathrm{mL})$ : collagen induced RA MH7A cells were treated by 10,20 , and $50 \mu \mathrm{g} / \mathrm{mL} \mathrm{PG}$, respectively for $24 \mathrm{~h}$ at $37^{\circ} \mathrm{C}$ in an atmosphere of $5 \% \mathrm{CO}_{2}$.

\section{Cell growth}

Cell growth was evaluated via Cell Counting Kit-8 assay (CCK-8; Dojindo, Japan) according to the manufacturer's protocols. Cells were inoculated into a 96 -well plate at a concentration of $6 \times 10^{4} /$ well and were cultured for $24 \mathrm{~h}$ $\left(37{ }^{\circ} \mathrm{C}, 5 \% \mathrm{CO}_{2}\right)$. Subsequently, the medium was replaced with fresh medium containing $\mathrm{PG}$ with different concentrations $(0,10,20$, and $50 \mu \mathrm{g} / \mathrm{mL})$ and cultured at $37^{\circ} \mathrm{C}$ for $24 \mathrm{~h}$. The absorbance of each well at $450 \mathrm{~nm}$ was determined using a multifunctional microplate reader Varioskan LUX (Thermo Scientific, Waltham, MA, USA). All experiments were conducted in triplicate.

\section{Apoptosis detection}

The RA-cells were treated with different concentrations of PG $(0,10,20$, and $50 \mu \mathrm{g} / \mathrm{mL})$ and then cultured at a density of $1 \times 10^{6}$ cells $/ \mathrm{mL}$ for $24 \mathrm{~h}$. After washing the cells twice with cold-phosphate buffered saline (PBS), which were resuspended in a $1 \times$ binding buffer and then mixed with Annexin V-FITC and PI solution (Sigma-Aldrich, Louis, MO, USA) for $15 \mathrm{~min}$ at room temperature in darkness. Cells were finally examined by a flow cytometer (Thermo Scientific, Waltham, MA, USA).

\section{Western blot assay}

The MH7A cells were induced by C II and treated with different concentrations of PG for $24 \mathrm{~h}(0,10,20,50 \mu \mathrm{g} / \mathrm{mL})$. The MH7A cells and cartilage tissues were ground by liquid nitrogen and lysed in a lysis buffer (Beyotime, 
A

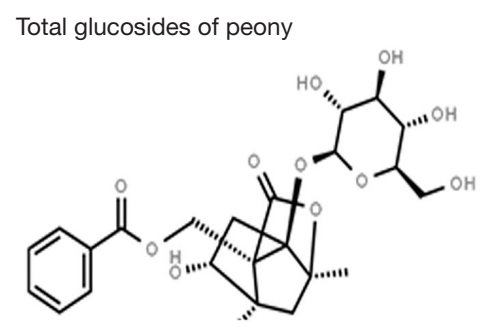

$\mathrm{C}_{23} \mathrm{H}_{28} \mathrm{O}_{11} \quad \mathrm{NW}: 480.4618$
B

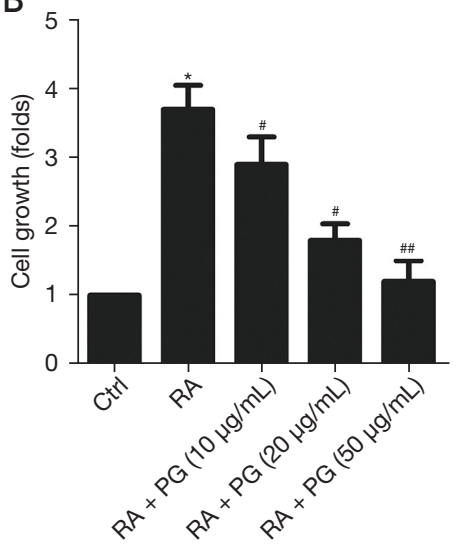

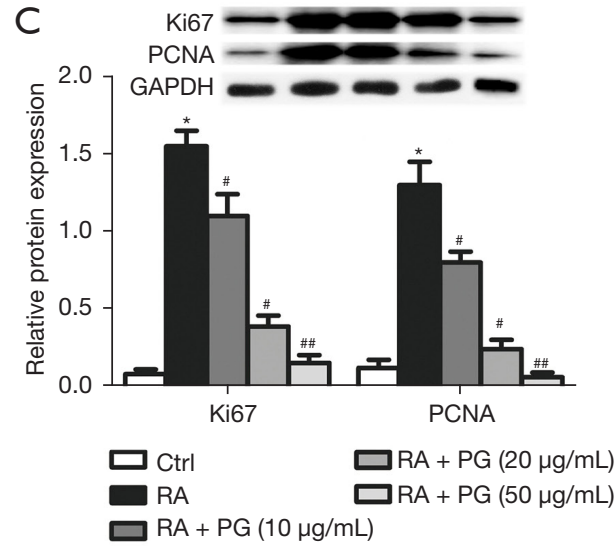

Figure 1 PG slowed down the growth of MH7A cells. MH7A cells were induced by C II for 24 h, and grouped as below: Control group, MH7A cells without any treatment; RA models, MH7A cells were induced by C II; RA + PG (10 $\mu \mathrm{g} / \mathrm{mL})$, RA models were treated with PG at $10 \mu \mathrm{g} / \mathrm{mL} ; \mathrm{RA}+\mathrm{PG}(20 \mu \mathrm{g} / \mathrm{mL})$, RA models were treated with PG at $20 \mu \mathrm{g} / \mathrm{mL} ; \mathrm{RA}+\mathrm{PG}(50 \mu \mathrm{g} / \mathrm{mL})$ : RA models were treated with PG at $50 \mu \mathrm{g} / \mathrm{mL}$. (A) The chemical structure of PG. (B) Cell growth was monitored by CCK-8 assay. (C) The protein expression of Ki67 and PCNA were measured by WB in each group. GAPDH served as an internal control. Results are from 3 independent experiments and data is expressed as mean $\pm \mathrm{SD}$. *, $\mathrm{P}<0.05$ vs. control;, $\mathrm{P}<0.05$, ${ }^{\text {\#\# }}, \mathrm{P}<0.05$ vs. RA models. RA, rheumatoid arthritis; $\mathrm{PG}$, total glucosides of peony; CCK-8, Cell Counting Kit-8.

Shanghai, China). The concentrations of proteins were determined using a bicinchoninic acid (BCA) Protein Assay Kit (Beyotime, Shanghai, China). A total of $20 \mu \mathrm{g}$ protein was isolated by $10 \%$ sodium dodecyl sulfatepolyacrylamide gel electrophoresis (SDS-PAGE), and then transferred to polyvinylidene fluoride membranes (PVDF; Sigma-Aldrich Co. St. Louis, MO, USA). Post blocking with $5 \%$ non-fat milk at room temperature for $1 \mathrm{~h}$, the samples were inoculated with primary antibodies including Ki-67 (sc-23900, 1:1,000, Santa Cruz Biotechnology,; SCB, Santa Cruz, CA, USA), proliferating cell nuclear antigen (PCNA; sc-71858, 1:1,000, SCB, USA), glyceraldehyde 3-phosphate dehydrogenase (GAPDH; sc66163, 1:1,000, SCB, USA), Bax (CAS\# ab182733, 1:2,000, Abcam, Cambridge, UK), Bcl-2 (\#ab692, 1:500, Abcam), NF- $\kappa B$ p65 (\#8242, 1:1,000, Cell Signaling Technology; CST, Danvers, MA, USA), p-p65 (\#3033, 1:1,000, CST, USA), STAT3 (\#9139, 1:1,000, CST, USA), and p-STAT3 (\#9145, 1:2,000, CST, USA), overnight at $4{ }^{\circ} \mathrm{C}$. The next day, membranes were incubated with a secondary antibody for $1.5 \mathrm{~h}$ at room temperature. The target protein bands were visualized using an Ultra High Sensitivity ECL Substrate Kit (Abcam).

\section{Animal models}

A protocol was prepared before the study without registration. All animal experiments were conducted in accordance with the National Institutes of Health (NIH) Guide for the Care and Use of Laboratory Animals (23) and were performed under a project license (No. hx201810062) granted by ethics board of Wuhan Huaxia Institute of Technology. A total of 50 female Wistar rats (170-260 g, 10 weeks old) were obtained from the Wuhan University Center for Animal Experiment/A3 Laboratory and placed in a controlled environment with free access to food and water. Rats were injected with $0.1 \mathrm{~mL}$ of complete Freund's complete adjuvant (FCA; Sigma-Aldrich Co. LLC, Shanghai, China) in the right hind paw. Post successful modeling, rats were divided into 5 groups $(\mathrm{n}=10)$ : Control group (Ctrl), without any treatment; RA, rheumatoid arthritis model; RA + PG (25 mg/kg), RA models were treated with $\mathrm{PG}$ at $25 \mathrm{mg} / \mathrm{kg}$; $\mathrm{RA}+\mathrm{PG}(50 \mathrm{mg} / \mathrm{kg}), \mathrm{RA}$ models were treated with $\mathrm{PG}$ at $50 \mathrm{mg} / \mathrm{kg} ; \mathrm{RA}+\mathrm{PG}(100 \mathrm{mg} / \mathrm{kg})$ : RA models were treated with $P G$ at $100 \mathrm{mg} / \mathrm{kg}$ (22). The mice were sacrificed for the subsequent experiments. 


\section{Histological analysis}

Synovial tissues were fixed in $4 \%$ formaldehyde and decalcified in $20 \%$ ethylenediamine tetra acetic acid (EDTA) for $24 \mathrm{~h}$. Then, the $4 \mu \mathrm{m}$ tissues were dehydrated, integrated into paraffin, and stained with hematoxylineosin (H\&E) and Safranin O, respectively. The morphologic changes of $\mathrm{H} \& \mathrm{E}$ - and Safranin O-stained sections were visualized by a light microscope (Nikon, Tokyo, Japan).

\section{Enzyme-linked immunosorbent assays}

Inflammatory cytokines including IL- 6 , TNF- $\alpha$, and IL-1 $\beta$ and immunomodulatory factor IL-10 were detected by an enzyme-linked immunosorbent assay kits (ELISA; CloudClone, Wuhan, China) according to the manufacturer's protocols. The optical density (OD) values at $450 \mathrm{~nm}$ were measured using a microplate reader (Thermo Scientific, USA).

\section{Statistical analysis}

Data are expressed as the means \pm standard deviation (SD) and repeated in at least triplicate. The different groups were statistically compared using one-way analysis of variance (ANOVA) followed by Bonferroni's post hoc test using SPSS 23.0 (IBM, Armonk, NY, USA). P $<0.05$ was considered to indicate a statistically significant difference.

\section{Results}

\section{PG slowed down the growth of MH7A cells}

In order to study the effect of PG on MH7A cells, cell growth was firstly measured. As shown in Figure $1 B$, cell growth was notably accelerated in the C II-induced RA group compared to the control. However, adding PG strongly suppressed cell growth compared with the C IIinduced RA group. The effect was enhanced with increase of PG (e.g., $50 \mu \mathrm{g} / \mathrm{mL}$ ). Cell proliferation-related proteins were monitored by western blot. As shown in Figure $1 C$, the levels of Ki67 and PCNA were notably elevated in the C II-induced RA group compared to the control. However, PG treatment strongly decreased the levels of Ki67 and PCNA dose-dependently. These results indicated that PG counteracted the accelerating effect of cell growth in MH7A cells.

\section{PG induced apoptosis in MH7A cells}

Resistance to apoptosis is a hallmark of RA-fibroblastlike synoviocytes (FLS). Consequently, we monitored the effect of different concentrations of PG $(0,10,20$, and $50 \mu \mathrm{g} / \mathrm{mL}$ ) on RA-MH7A cell apoptosis after treatment for $24 \mathrm{~h}$ (Figure 2A,2B). Furthermore, western blot analysis was used to detect apoptosis-related proteins in the 4 groups (Figure $2 C-2 E$ ). The results revealed that the levels of caspase- 3 and $\mathrm{Bcl}-2$ protein were notably elevated in the C II-induced RA group compared to the control, while the levels of Bax were notably suppressed. PG treatment strongly decreased the levels of caspase- 3 and Bcl-2 with increase of Bax dose-dependently. Besides, the ratio of $\mathrm{Bax} / \mathrm{Bcl}-2$ was also promoted in MH7A cells treated with PG compared with C II-induced RA group. These results demonstrated that PG induced apoptosis by regulating the expression of apoptosis-related proteins in MH7A cells.

\section{PG attenuated inflammation in MH7A cells}

To determine the effect of PG on inflammatory response, ELISA assays were used to detect IL-6 (Figure 3A), IL10 (Figure 3B), TNF- $\alpha$ (Figure 3C), and IL-1 $\beta$ (Figure 3D) production in RA-MH7A at the protein levels. RA-MH7A were divided into 5 groups which were treated with various concentrations of PG $(0,10,20$, and $50 \mu \mathrm{g} / \mathrm{mL})$ for $2 \mathrm{~h}$. As Figure 3 illustrates, the levels of IL-6, TNF- $\alpha$, and IL- $1 \beta$ were significantly increased in RA group compared to the control, while IL-10 was decreased. On the contrary, PG counteracted the increase of IL- 6 , TNF- $\alpha$, and IL- $1 \beta$ levels. IL-10 level was markedly enhanced compared to the RA group (Figure 3A-3D).

\section{$P G$ restored the histological injuries in cartilage tissues}

The H\&E staining (Figure $4 A$ ) revealed that compared with the control group, the structure of the lesion site in the RA model group became loose, with a large number of synovial cells proliferating and destroying the cartilage margins. Safranin O staining (Figure 4B) showed that in the control group, the cartilage area was dyed red and the bone area was dyed blue. Nevertheless, the red of the cartilage area disappeared, and the cartilage tissue was severely damaged in the FCA-induced RA group. Treatment with PG dosedependently ameliorated pathological injuries in cartilage region (Figure 4A,4B). The results from Safranin O staining were consistent with $\mathrm{H} \& \mathrm{E}$ staining. Taken together, PG 
A
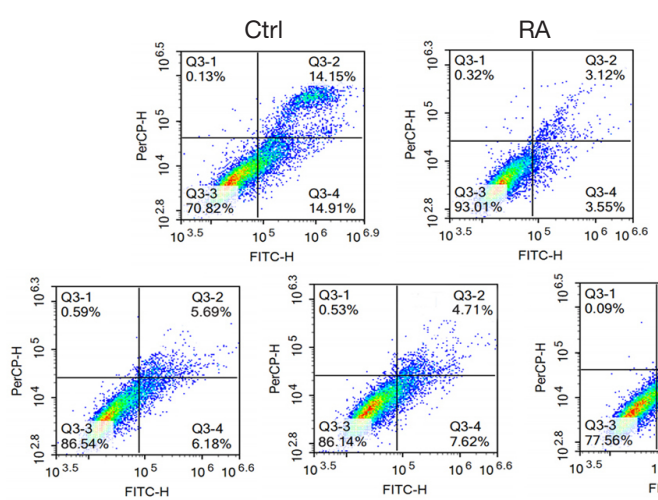

$R A+P G(10 \mu g / m L)$

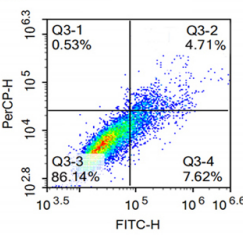

$R A+P G(20 \mu g / m L)$

C

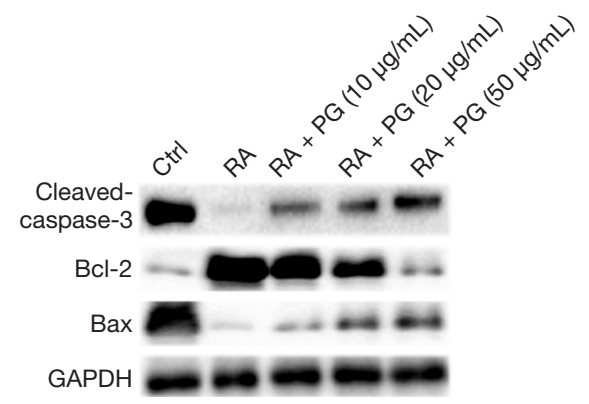

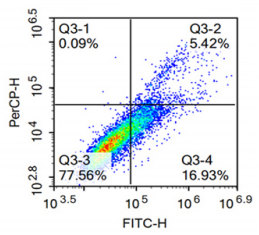

$R A+P G(50 \mu g / m L)$

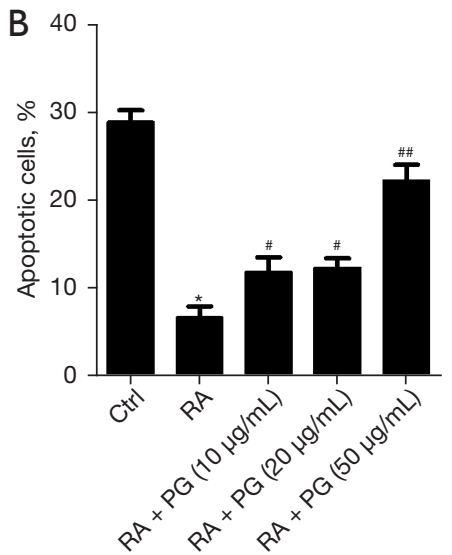

$\mathrm{E}$
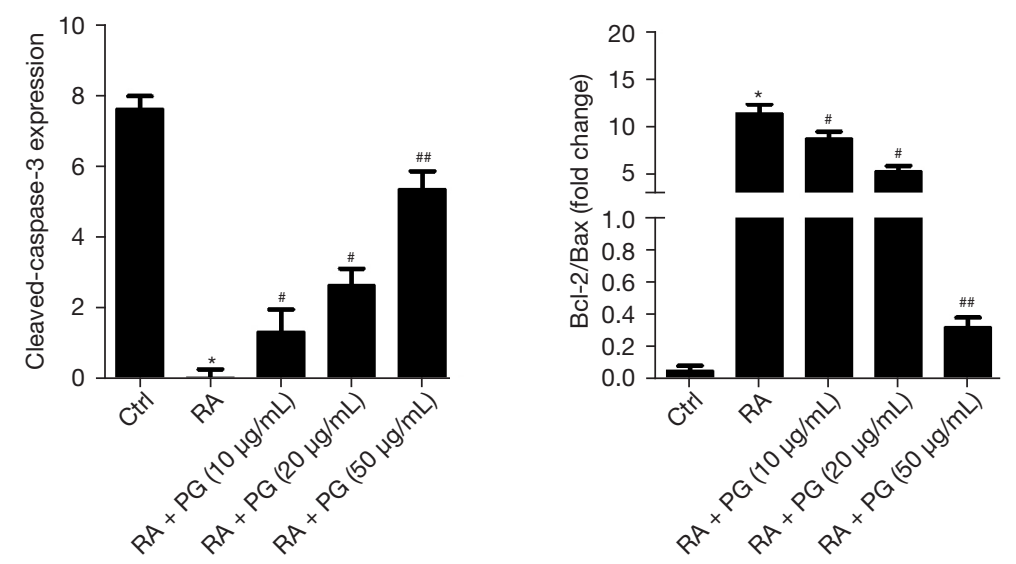

Figure 2 PG induced apoptotic in MH7A cells. MH7A cells were induced by C II for $24 \mathrm{~h}$, and grouped as below: Ctrl group, MH7A cells without any treatment; RA models, MH7A cells were induced by C II; RA + PG (10 $\mu \mathrm{g} / \mathrm{mL})$, RA models were treated with PG at $10 \mu \mathrm{g} / \mathrm{mL}$; $\mathrm{RA}+\mathrm{PG}(20 \mu \mathrm{g} / \mathrm{mL})$, RA models were treated with PG at $20 \mu \mathrm{g} / \mathrm{mL} ; \mathrm{RA}+\mathrm{PG}(50 \mu \mathrm{g} / \mathrm{mL})$ : RA models were treated with PG at $50 \mu \mathrm{g} / \mathrm{mL}$. (A) Flow cytometry was used to detect cell apoptosis following a $24 \mathrm{~h}$ treatment of cells with different concentrations of PG. (B) The percentage of apoptotic cells in each group. (C) The protein expression of caspase-3, Bcl-2, and Bax were measured by WB in each group. (D,E) The bar graph displayed the quantification of caspase-3 and the ratio of Bax/Bcl-2 in all groups. GAPDH served as an internal control. Results were from three independent experiments and data was expressed as mean $\pm \mathrm{SD}$. *, $\mathrm{P}<0.05$ vs. control; ${ }^{\#}, \mathrm{P}<0.05,{ }^{\#}, \mathrm{P}<0.05$ vs. RA group. RA, rheumatoid arthritis; PG, total glucosides of peony; GAPDH, glyceraldehyde 3-phosphate dehydrogenase; WB, western blot.

restored the histological injuries in cartilage tissues.

\section{$P G$ restored the histological injuries by reducing the levels of inflammatory cytokines in vivo}

The cytokines IL-6 (Figure 5A), IL-10 (Figure 5B), TNF- $\alpha$ (Figure 5C), and IL-1 $\beta$ (Figure 5D) were identified using ELISA assays. The results showed that the levels of IL- 6 , TNF- $\alpha$, and IL- $1 \beta$ were significantly increased in FCA-induced RA group compared to the control, while IL-10 was decreased. The result of IL-10 was consistent with the report by Daien et al. (24) and Bankó et al. (25). However, PG counteracted the increase of IL-6, TNF- $\alpha$, and IL- $1 \beta$ levels. On the contrary, IL10 level was markedly enhanced compared to the FCAinduced RA group (Figure $5 A-5 D$ ). Increase of IL-10 indicated that $\mathrm{PG}$ promoted $\mathrm{B}$ cells to develop adaptive immunity $(26,27)$. All these results indicated that PG restored the histological injuries by reducing the levels of inflammatory cytokines in vivo. 

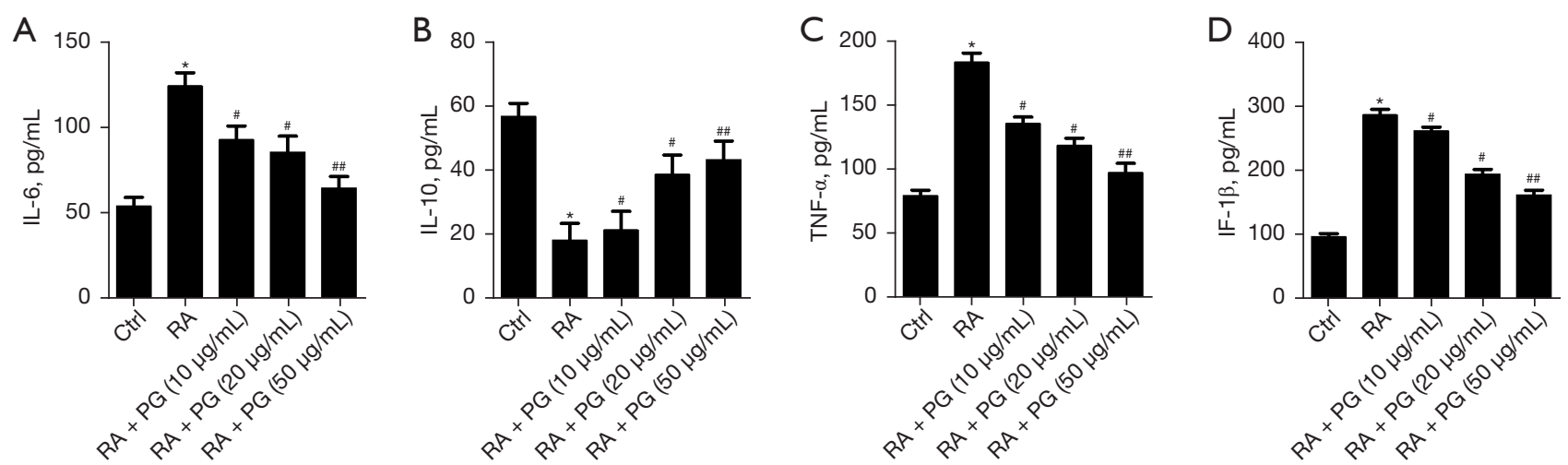

Figure 3 PG attenuated inflammation in RA-MH7A. MH7A cells were induced by C II for $24 \mathrm{~h}$, and grouped as below: Ctrl group, MH7A cells without any treatment; RA models, MH7A cells were induced by C II; RA + PG (10 $\mu \mathrm{g} / \mathrm{mL})$, RA models were treated with PG at $10 \mu \mathrm{g} / \mathrm{mL} ; \mathrm{RA}+\mathrm{PG}(20 \mu \mathrm{g} / \mathrm{mL})$, RA models were treated with PG at $20 \mu \mathrm{g} / \mathrm{mL} ; \mathrm{RA}+\mathrm{PG}(50 \mu \mathrm{g} / \mathrm{mL})$ : RA models were treated with PG at $50 \mu \mathrm{g} / \mathrm{mL}$. The levels of (A) IL-6, (B) IL-10, (C) TNF- $\alpha$, and (D) IL- $\beta$ were detected by ELISA in each group. Results are from 3 independent experiments and data is expressed as mean $\pm \mathrm{SD}$. *, $\mathrm{P}<0.05$ vs. control; ${ }^{\#}, \mathrm{P}<0.05,{ }^{\#}, \mathrm{P}<0.05$ vs. RA group. Ctrl, control group; RA, rheumatoid arthritis; PG, total glucosides of peony; FCA, Freund's complete adjuvant; IL-6, interleukin-6; IL-10, interleukin-10; TNF- $\alpha$; tumor necrosis factor- $\alpha$; ELISA, enzyme-linked immunosorbent assay.
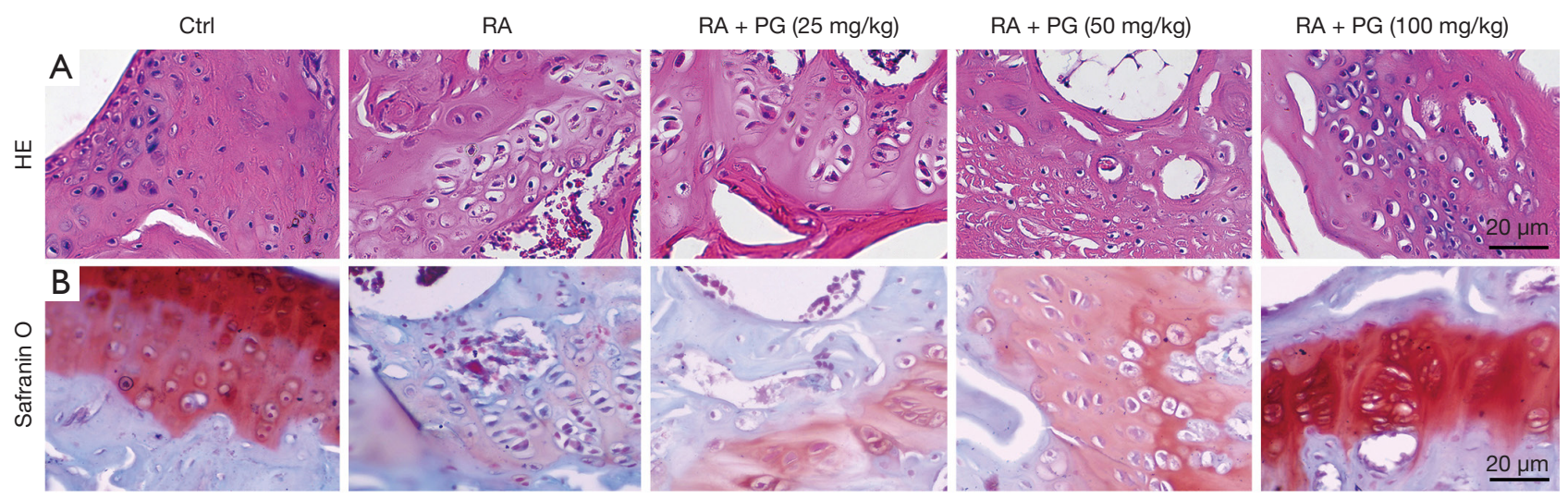

Figure 4 PG restored the histological injuries in cartilage tissues. Rats were injected with $0.1 \mathrm{~mL}$ of FCA in the right hind paw and grouped as below: Ctrl, without any treatment; RA, rheumatoid arthritis model; RA + PG (25 mg/kg), RA models were treated with PG at $25 \mathrm{mg} / \mathrm{kg}$; $\mathrm{RA}+\mathrm{PG}(50 \mathrm{mg} / \mathrm{kg})$, RA models were treated with PG at $50 \mathrm{mg} / \mathrm{kg}$; RA + PG (100 mg/kg): RA models were treated with PG at $100 \mathrm{mg} / \mathrm{kg}$. Histological change was monitored by H\&E staining (A) and Safranin O staining (B) in each group (Manifestation $\times 200$ ). Ctrl, control group; RA, rheumatoid arthritis; PG, total glucosides of peony; FCA, Freund's complete adjuvant; H\&E, hematoxylin and eosin.

\section{$P G$ ameliorated $R A$ by inactivation of the $N F-\kappa B / S T A T 3$ patbway in vivo}

We further investigated the molecular mechanism. Expression of relative proteins were measured by western blot assay. As shown in Figure 6A, phosphorylation of NF$\kappa \mathrm{B}$ and STAT3 was elevated in the FCA-induced RA group, compared with the control group. The PG treatment dosedependently reduced the protein expression of p-p65 and
p-STAT3. The results illustrated that PG restrained the phosphorylation of NF- $\mathrm{KB}$ and STAT3. Even a high dose of PG had a significant inhibitory effect on phosphorylation of p65 and STAT3, which was further verified after adding their agonist (Figure $6 B, 30 \mathrm{mg} / \mathrm{kg}$ Betulinic acid, NF- $\mathrm{KB}$ agonist; Figure $6 C, 1 \mathrm{mg} / \mathrm{kg}$ Colivelin, STAT3 agonist). Taken together, these results indicated that PG ameliorated RA by deactivation of the NF-kB/STAT3 pathway in vivo. 

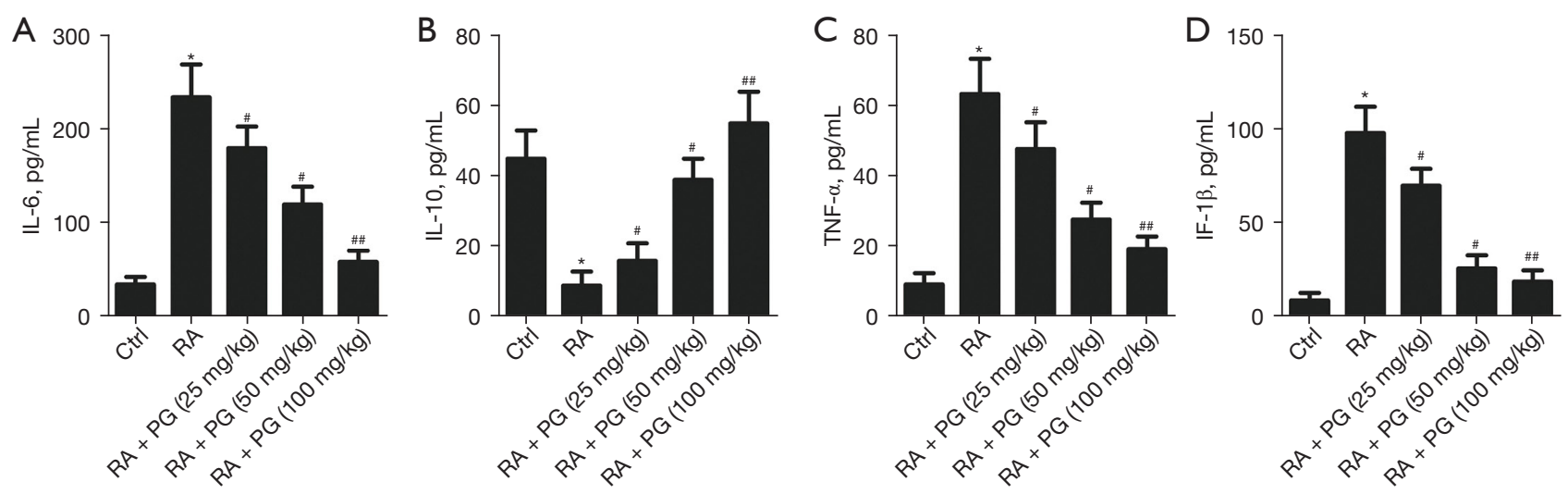

Figure 5 PG restored the histological injuries by reducing the levels of inflammatory cytokines in vivo. Rats were injected with $0.1 \mathrm{~mL}$ of FCA in the right hind paw and grouped as below: Ctrl, without any treatment; RA, Rheumatoid arthritis model; RA + PG (25 mg/kg), RA models were treated with PG at $25 \mathrm{mg} / \mathrm{kg}$; RA + PG (50 mg/kg), RA models were treated with PG at $50 \mathrm{mg} / \mathrm{kg}$; RA + PG (100 mg/kg): RA models were treated with PG at $100 \mathrm{mg} / \mathrm{kg}$. The levels of (A) IL-6, (B) IL-10, (C) TNF- $\alpha$, and (D) IL- $\beta$ were detected by ELISA in each group. Results are from 3 independent experiments and data is expressed as mean $\pm \mathrm{SD} .{ }^{*}, \mathrm{P}<0.05$ vs. control; ${ }^{*}, \mathrm{P}<0.05,{ }^{\#}, \mathrm{P}<0.05$ vs. $\mathrm{RA}$ group. Ctrl, control group; RA, rheumatoid arthritis; PG, total glucosides of peony; FCA, Freund's complete adjuvant; IL-6, interleukin-6; IL-10, interleukin-10; TNF- $\alpha$; tumor necrosis factor- $\alpha$; ELISA, enzyme-linked immunosorbent assay.

\section{Discussion}

As an autoimmune disease, RA is marked by infiltration of inflammatory cells and proliferation of synovial fibroblasts. On average, RA reduces patient lifespan by up to 12 years due to the limited efficacy of treatment $(28,29)$. Various therapies such as non-steroidal drugs, glucocorticoids, antirheumatic drugs, and biological agents are available; however, RA patients who are treated long-term with biologic agents are still at risk of infections and other therioma (7-9).

Chinese medicinal herbs contain a variety of natural substances, the isolated extracts from which have a wide range of biological activity, and minimal side-effects. The bioactive ingredient extracted from root of Paeonia lactiflora Pall, known as PG, was recognized as a disease-modifying drug for RA in 1998. Previous studies (30) have shown that PG markedly intercepts the progression of adjuvant arthritis by mediating cyclic adenosine 5'-monophosphate (cAMP) and inhibiting IL-1, TNF- $\alpha$, IL-6, and prostaglandin $\mathrm{E}_{2}\left(\mathrm{PGE}_{2}\right)$. The occurrence of RA is accompanied by the release of cytokines such as TNF- $\alpha$, IL-8, IL- 6 , and IL-1. RA-FLS is involved in RA initiation through the production of pro-inflammatory cytokines (31). Another study revealed that $\mathrm{PG}$ reduced the proinflammatory cytokine production in oral lichen planus and inhibited cell proliferation diabetic nephropathy rats (17).
Consistent with previous reports, our results firstly showed that PG suppressed inflammation both in vitro and in vivo by suppressing the activity of NF- $\mathrm{kB} / \mathrm{STAT} 3$ signaling pathway, and restored the histological injuries by regulating inflammatory cytokines in FCA-induced RA rats. Furthermore, cell death certainly contributes, at least in part, to the reduction in pro-inflammatory cytokines.

Synovial hyperplasia is characterized by increased proliferation and decreased apoptosis of RA-FLS, which contribute to chronic inflammation of synovial and destruction of articular cartilage (32). In previous reports, several drugs have been shown to inhibit fibroblast-like synovial cell proliferation in arthritis $(33,34)$. Similar to other drugs, PG has been shown to remarkably impede the proliferation of synoviocytes in collagen-induced arthritis (30). In this study, PG inhibited RA-MH7A cell proliferation with a concentration-dependent pattern. In addition, down-regulation of Bcl-2 protein expression and up-regulation of Bax protein expression indicated that PG could induce apoptosis through the mitochondrial pathway, which activates caspase- 3 and caspase-9, leading to intracellular apoptosis pathways.

The protein complex NF- $\kappa \mathrm{B}$ is an essential nuclear transcription factor that can affect cell survival, mutation, and proliferation. It can be triggered by serum, insulin, growth factor, radiation, chemotherapy drugs, and other stimulators. It has been confirmed that the NF- $\mathrm{kB}$ signaling 
A

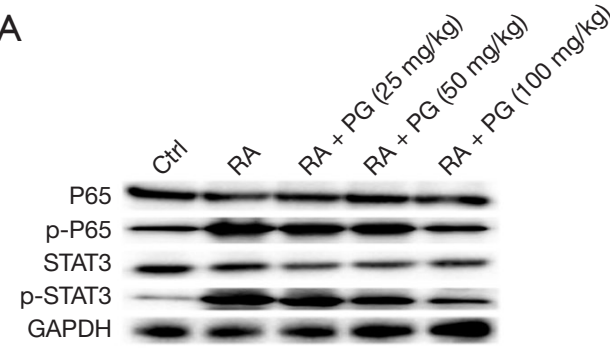

B

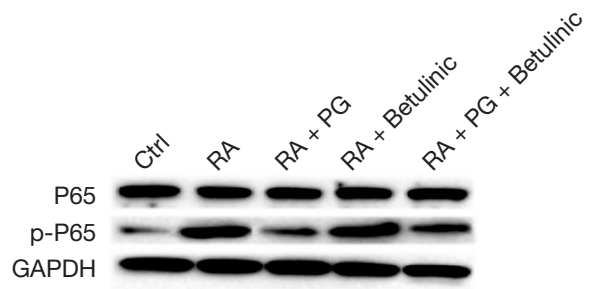

C

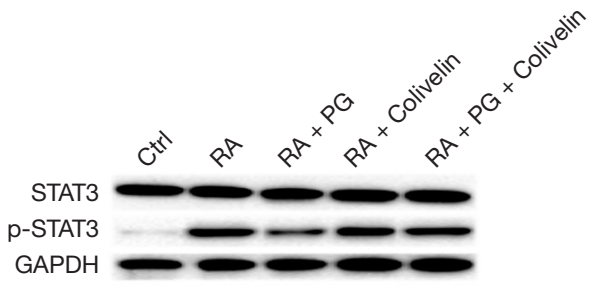

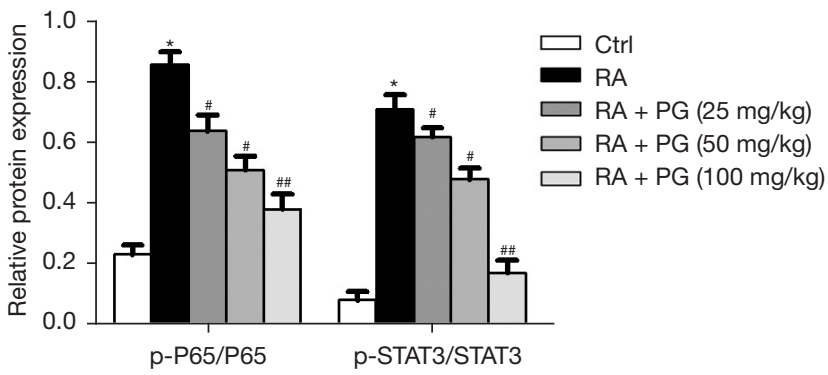
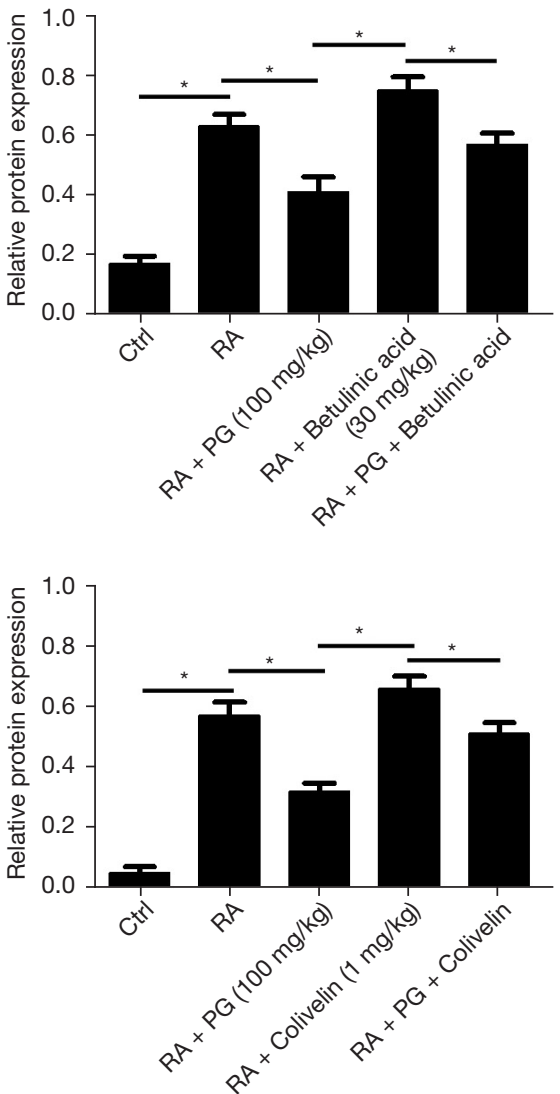

Figure 6 PG ameliorated RA by inactivation of the NF-kB/STAT3 pathway in vivo. Rats were injected with $0.1 \mathrm{~mL}$ of FCA in the right hind paw and grouped as below: Ctrl, without any treatment; RA, Rheumatoid arthritis model; RA + PG $(25 \mathrm{mg} / \mathrm{kg})$, RA models were treated with PG at $25 \mathrm{mg} / \mathrm{kg}$; RA + PG (50 mg/kg), RA models were treated with PG at $50 \mathrm{mg} / \mathrm{kg}$; RA + PG (100 mg/kg): RA models were treated with PG at $100 \mathrm{mg} / \mathrm{kg}$. (A) Phosphorylation of p65 and STAT3 was monitored by WB. After adding NF- $\mathrm{kB}$ agonist Betulinic acid (B) and STAT3 agonist Colivelin (C), phosphorylation of p65 and STAT3 was monitored by WB. GAPDH served as an internal control. Results are from 3 independent experiments and data are expressed as mean $\pm \mathrm{SD}$. ${ }^{*}, \mathrm{P}<0.05$ vs. control; ${ }^{*}, \mathrm{P}<0.05,{ }^{\# \#}, \mathrm{P}<0.05 v s$. RA group. Ctrl, Control group; RA, rheumatoid arthritis; PG, total glucosides of peony; FCA, Freund's complete adjuvant; NF-кB, nuclear factor-kappa B; STAT3, signal transducer and activator of transcription; WB, western blot; GAPDH, glyceraldehyde 3-phosphate dehydrogenase.

pathway plays a major role in tumorigenesis, development, invasion, and metastasis (35). The subunit NF- $\mathrm{\kappa B}$ p65 is a

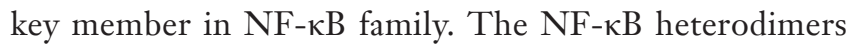

are phosphorylated and translocated into the nucleus, where they bind to genes at the binding site and initiate transcription of proinflammatory genes (36). Therefore, 
regulating NF- $\kappa \mathrm{B}$ activity is a plausible treatment for inflammatory diseases. In different cell types and tissues, STAT3 is widely expressed and plays a key role in regulating cell proliferation, survival, and inflammation (37). Wang et al. reported that PG suppressed the dissociation of I $\mathrm{B} \alpha \alpha$ and reduced the levels of IL- 6 and TNF- $\alpha$ in oral lichen planus (17). Besides, PG has been reported to promote macrophage proliferation by activating the JAK2/STAT3 pathway in diabetic nephropathy rats (21). Similarly, in the present study, we found that PG dose-dependently decreased the phosphorylation level of NF- $\mathrm{NB} \mathrm{p} 65$, and the reduction of NF- $\mathrm{KB}$ p 65 further decreased IL-6 level and STAT3 phosphorylation, which ultimately alleviated FCAinduced cartilage tissue injury.

In conclusion, our study revealed a novel mechanism of PG protection against RA. In this study, we showed that PG $(10,20$, and $50 \mu \mathrm{g} / \mathrm{mL})$ significantly suppressed cell growth in MH7A cells in a dose-dependent manner. Besides, PG markedly restored the histological injuries of cartilage tissue by regulating inflammatory cytokines and immunomodulatory factors in FCA-induced RA rats via the NF- $\kappa \mathrm{B} / \mathrm{STAT} 3$ pathway. Our findings indicate that PG mitigates RA by suppressing the excessive proliferation of synovial cells, cartilage injury, and inflammation via deactivation of the NF- $\mathrm{kB} / \mathrm{STAT} 3$ pathway. Nonetheless, these results need to be verified through animal studies and additional mechanisms by which on further RA treatment and prognosis in future studies.

\section{Acknowledgments}

Funding: This study was supported by the scientific research program of Hubei Provincial Department of Education (B2020311).

\section{Footnote}

Reporting Checklist: The authors have completed the ARRIVE reporting checklist. Available at https://atm. amegroups.com/article/view/10.21037/atm-21-6187/rc

Data Sharing Statement: Available at https://atm.amegroups. com/article/view/10.21037/atm-21-6187/dss

Conflicts of Interest: All authors have completed the ICMJE uniform disclosure form (available at https://atm. amegroups.com/article/view/10.21037/atm-21-6187/coif). The authors have no conflicts of interest to declare.
Ethical Statement: The authors are accountable for all aspects of the work in ensuring that questions related to the accuracy or integrity of any part of the work are appropriately investigated and resolved. All animal experiments were conducted in accordance with the National Institutes of Health (NIH) Guide for the Care and Use of Laboratory Animals and were performed under a project license (No. hx201810062) granted by ethics board of Wuhan Huaxia Institute of Technology.

Open Access Statement: This is an Open Access article distributed in accordance with the Creative Commons Attribution-NonCommercial-NoDerivs 4.0 International License (CC BY-NC-ND 4.0), which permits the noncommercial replication and distribution of the article with the strict proviso that no changes or edits are made and the original work is properly cited (including links to both the formal publication through the relevant DOI and the license). See: https://creativecommons.org/licenses/by-nc-nd/4.0/.

\section{References}

1. Ahmed S. Green tea polyphenol epigallocatechin 3-gallate in arthritis: progress and promise. Arthritis Res Ther 2010;12:208.

2. Lorenzo M. Rheumatoid arthritis. Foot Ankle Clin 2007;12:525-37, vii.

3. Cooles FA, Isaacs JD. Pathophysiology of rheumatoid arthritis. Curr Opin Rheumatol 2011;23:233-40.

4. Meesters JJ, Verhoef J, Liem IS, et al. Validity and responsiveness of the World Health Organization Disability Assessment Schedule II to assess disability in rheumatoid arthritis patients. Rheumatology (Oxford) 2010;49:326-33.

5. Kiadaliri AA, Felson DT, Neogi T, et al. Brief Report: Rheumatoid Arthritis as the Underlying Cause of Death in Thirty-One Countries, 1987-2011: Trend Analysis of World Health Organization Mortality Database. Arthritis Rheumatol 2017;69:1560-5.

6. Gupta M, Sasmal S, Mukherjee A. Therapeutic Effects of Acetone Extract of Saraca asoca Seeds on Rats with Adjuvant-Induced Arthritis via Attenuating Inflammatory Responses. ISRN Rheumatol 2014;2014:959687.

7. Kroesen S, Widmer AF, Tyndall A, et al. Serious bacterial infections in patients with rheumatoid arthritis under anti-TNF-alpha therapy. Rheumatology (Oxford) 2003;42:617-21.

8. Listing J, Strangfeld A, Kary S, et al. Infections in patients 
with rheumatoid arthritis treated with biologic agents. Arthritis Rheum 2005;52:3403-12.

9. Greenberg JD, Reed G, Kremer JM, et al. Association of methotrexate and tumour necrosis factor antagonists with risk of infectious outcomes including opportunistic infections in the CORRONA registry. Ann Rheum Dis 2010;69:380-6.

10. Lu Z, Morinaga $\mathrm{O}$, Tanaka $\mathrm{H}$, et al. A quantitative ELISA using monoclonal antibody to survey paeoniflorin and albiflorin in crude drugs and traditional Chinese herbal medicines. Biol Pharm Bull 2003;26:862-6.

11. He DY, Dai SM. Anti-inflammatory and immunomodulatory effects of paeonia lactiflora pall., a traditional chinese herbal medicine. Front Pharmacol 2011;2:10.

12. Wu H, Wei W, Song L, et al. Paeoniflorin induced immune tolerance of mesenteric lymph node lymphocytes via enhancing beta 2 -adrenergic receptor desensitization in rats with adjuvant arthritis. Int Immunopharmacol 2007;7:662-73.

13. Su J, Zhang P, Zhang JJ, et al. Effects of total glucosides of paeony on oxidative stress in the kidney from diabetic rats. Phytomedicine 2010;17:254-60.

14. Zhou Y, Jin L, Kong F, et al. Clinical and immunological consequences of total glucosides of paeony treatment in Sjögren's syndrome: A randomized controlled pilot trial. Int Immunopharmacol 2016;39:314-9.

15. Zhu Q, Qi X, Wu Y, et al. Clinical study of total glucosides of paeony for the treatment of diabetic kidney disease in patients with diabetes mellitus. Int Urol Nephrol 2016;48:1873-80.

16. Huang XT, Wang B, Zhang WH, et al. Total glucosides of paeony suppresses experimental autoimmune uveitis in association with inhibition of Th1 and Th2 cell function in mice. Int J Immunopathol Pharmacol 2018;32:394632017751547.

17. Wang Y, Zhang H, Du G, et al. Total glucosides of paeony (TGP) inhibits the production of inflammatory cytokines in oral lichen planus by suppressing the NF- B signaling pathway. Int Immunopharmacol 2016;36:67-72.

18. Zhang ZH, Xie DD, Xu S, et al. Total glucosides of paeony inhibits lipopolysaccharide-induced proliferation, migration and invasion in androgen insensitive prostate cancer cells. PLoS One 2017;12:e0182584.

19. Luo J, Jin DE, Yang GY, et al. Total glucosides of paeony for rheumatoid arthritis: a protocol for a systematic review. BMJ Open 2016;6:e010116.

20. Sedhom MAK. Cytokines and STAT3 signalling in autoimmune diseases. UQ Diamantina Institute, The University of Queensland, 2015. doi: 10.14264/ uql.2015.806.

21. Wang K, Wu YG, Su J, et al. Total glucosides of paeony regulates JAK2/STAT3 activation and macrophage proliferation in diabetic rat kidneys. Am J Chin Med 2012;40:521-36.

22. Jia XY, Chang Y, Sun XJ, et al. Total glucosides of paeony inhibit the proliferation of fibroblast-like synoviocytes through the regulation of $\mathrm{G}$ proteins in rats with collageninduced arthritis. Int Immunopharmacol 2014;18:1-6.

23. ILAR (Institute for Laboratory Animal Research). Guide for the Care and Use of Laboratory Animals. 8th ed. Washington, DC: National Academies Press. 2011.

24. Daien CI, Gailhac S, Mura T, et al. Regulatory B10 cells are decreased in patients with rheumatoid arthritis and are inversely correlated with disease activity. Arthritis Rheumatol 2014;66:2037-46.

25. Bankó Z, Pozsgay J, Szili D, et al. Induction and Differentiation of IL-10-Producing Regulatory B Cells from Healthy Blood Donors and Rheumatoid Arthritis Patients. J Immunol 2017;198:1512-20.

26. Vadasz Z, Haj T, Kessel A, et al. B-regulatory cells in autoimmunity and immune mediated inflammation. FEBS Lett 2013;587:2074-8.

27. Gorosito Serrán M, Fiocca Vernengo F, Beccaria CG, et al. The regulatory role of $\mathrm{B}$ cells in autoimmunity, infections and cancer: Perspectives beyond IL10 production. FEBS Lett 2015;589:3362-9.

28. Wasserman AM. Diagnosis and management of rheumatoid arthritis. Am Fam Physician 2011;84:1245-52.

29. Doss HM, Ganesan R, Rasool M. Trikatu, an herbal compound ameliorates rheumatoid arthritis by the suppression of inflammatory immune responses in rats with adjuvant-induced arthritis and on cultured fibroblast like synoviocytes via the inhibition of the NFאB signaling pathway. Chem Biol Interact 2016;258:175-86.

30. Xu HM, Wei W, Jia XY, et al. Effects and mechanisms of total glucosides of paeony on adjuvant arthritis in rats. J Ethnopharmacol 2007;109:442-8.

31. Brennan FM, McInnes IB. Evidence that cytokines play a role in rheumatoid arthritis. J Clin Invest 2008;118:3537-45.

32. Baier A, Meineckel I, Gay S, et al. Apoptosis in rheumatoid arthritis. Curr Opin Rheumatol 2003;15:274-9.

33. Gong Y, Huang T, Yu Q, et al. Sorafenib suppresses proliferation rate of fibroblast-like synoviocytes through the arrest of cell cycle in experimental adjuvant arthritis. J 
Pharm Pharmacol 2021;73:32-9.

34. Xie C, Jiang J, Liu J, et al. Ginkgolide B attenuates collagen-induced rheumatoid arthritis and regulates fibroblast-like synoviocytes-mediated apoptosis and inflammation. Ann Transl Med 2020;8:1497.

35. Lin A, Karin M. NF-kappaB in cancer: a marked target. Semin Cancer Biol 2003;13:107-14.

36. Baldwin AS Jr. The NF-kappa B and I kappa B proteins:

Cite this article as: $\mathrm{Fu} \mathrm{M}$, Sang $\mathrm{X}$, Cheng H. Total glucosides of peony induce fibroblast-like synovial apoptosis, and ameliorate cartilage injury via blocking the NF-кB/STAT3 pathway. Ann Transl Med 2022;10(2):51. doi: 10.21037/atm-21-

6187 new discoveries and insights. Annu Rev Immunol 1996;14:649-83.

37. He M, Wang C, Sun JH, et al. Roscovitine attenuates intimal hyperplasia via inhibiting NF- $\mathrm{B}$ and STAT3 activation induced by TNF- $\alpha$ in vascular smooth muscle cells. Biochem Pharmacol 2017;137:51-60.

(English Language Editor: J. Jones) 